Article

\title{
The Intermediate Filament Synemin Regulates Non-Homologous End Joining in an ATM-Dependent Manner
}

\author{
Sara Sofia Deville ${ }^{1,2}$, Anne Vehlow ${ }^{1,3,4}$, Sarah Förster ${ }^{1,2}$, Ellen Dickreuter ${ }^{1}$, Kerstin Borgmann ${ }^{5}$ \\ and Nils Cordes $1,2,4,6, *$ \\ 1 OncoRay-National Center for Radiation Research in Oncology, Faculty of Medicine Carl Gustav Carus, \\ Technische Universität Dresden, 01307 Dresden, Germany; \\ SaraSofia.Deville@uniklinikum-dresden.de (S.S.D.); anne.vehlow@nct-dresden.de (A.V.); \\ Sarah.Foerster@ukbonn.de (S.F.); ellen.dickreuter@gmail.com (E.D.) \\ 2 Helmholtz-Zentrum Dresden-Rossendorf (HZDR), Institute of Radiooncology-OncoRay, \\ 01328 Dresden, Germany \\ 3 National Center for Tumor Diseases, Partner Site Dresden: German Cancer Research Center, \\ 69120 Heidelberg, Germany \\ 4 German Cancer Consortium, Partner Site Dresden: German Cancer Research Center, \\ 69120 Heidelberg, Germany \\ 5 Laboratory of Radiobiology and Experimental Radiation Oncology, University Medical Center \\ Hamburg-Eppendorf, 20246 Hamburg, Germany; borgmann@uke.de \\ 6 Department of Radiotherapy and Radiation Oncology, University Hospital Carl Gustav Carus, \\ Technische Universität Dresden, 01307 Dresden, Germany \\ * Correspondence: Nils.Cordes@OncoRay.de; Tel.: +49-(0)351-458-7401; Fax: +49-(0)351-458-7311
}

Received: 14 May 2020; Accepted: 24 June 2020; Published: 28 June 2020

\begin{abstract}
The treatment resistance of cancer cells is a multifaceted process in which DNA repair emerged as a potential therapeutic target. DNA repair is predominantly conducted by nuclear events; yet, how extra-nuclear cues impact the DNA damage response is largely unknown. Here, using a high-throughput RNAi-based screen in three-dimensionally-grown cell cultures of head and neck squamous cell carcinoma (HNSCC), we identified novel focal adhesion proteins controlling DNA repair, including the intermediate filament protein, synemin. We demonstrate that synemin critically regulates the DNA damage response by non-homologous end joining repair. Mechanistically, synemin forms a protein complex with DNA-PKcs through its C-terminal tail domain for determining DNA repair processes upstream of this enzyme in an ATM-dependent manner. Our study discovers a critical function of the intermediate filament protein, synemin in the DNA damage response, fundamentally supporting the concept of cytoarchitectural elements as co-regulators of nuclear events.
\end{abstract}

Keywords: synemin; DNA-PKcs; ATM; DNA repair; NHEJ; radiosensitivity; HNSCC

\section{Introduction}

DNA double strand breaks (DSB) are the most lethal damages generated by genotoxic agents, such as ionizing radiation (IR) and chemotherapeutics [1], accounting for the therapeutic benefit of current cancer treatment modalities. These complex DNA lesions are repaired by two major cellular mechanisms: Non-homologous end joining (NHEJ) and homologous recombination (HR) [2,3]. Hence, targeting the DNA repair machinery is considered a potentially effective approach for eradicating cancer cells, and several pharmacological inhibitors are being currently tested in clinical trials [4] (www.clinicaltrials.org). 
While HR is mostly regarded as an error-free repair process restricted to the S/G2 phase, NHEJ is error-prone and active throughout the mammalian cell cycle [5]. During NHEJ, DSB are recognized by the binding of the Ku70/Ku80 heterodimers to broken DNA ends, followed by the recruitment and activation of the apical DNA repair kinases, DNA protein kinase catalytic subunit (DNA-PKcs) and Ataxia telangiectasia mutated (ATM) [2]. Subsequently, the nucleases Artemis, Aprataxin or APLF are recruited to complete the end processing, together with ligases IV, XRCC4, XLF and PAXX, as well as numerous chromatin and nuclear matrix remodeling enzymes to allow for the maintenance of genomic stability [5].

In addition to our deep understanding of nuclear DSB repair events, recent work has identified several extra-nuclear factors, which fundamentally and context-dependently modify DNA repair via yet to be determined mechanisms. Examples of such key co-regulators are growth factor receptors and integrin cell adhesion molecules, connecting tumor cells to the extracellular matrix (ECM), and its stiffness in juxtamembrane multiprotein complexes, called focal adhesions [6-8]. To date, a variety of focal adhesion proteins (FAP), such as $\beta 1$ integrin, PINCH1, FHL2, focal adhesion kinase, vimentin and caveolin-1 have been demonstrated to significantly confer tumor resistance to genotoxic agents by modulating the repair of DSB upon radiochemotherapy [9-14]. In addition, accumulating evidences suggest that cytoplasmic FAP signaling is linked to nuclear repair dynamics through components of the DNA repair machinery, including DNA-PKcs, ATM, BRCA1, RAD51 and c-Abl [15].

To systematically search for novel FAP candidates driving the cancer therapy resistome by linking extracellular cues to intracellular DNA repair decisions, we conducted a high-throughput RNA interference screen combined with X-ray irradiation in more physiologically three-dimensional (3D) ECM based cell cultures of human head and neck squamous cell carcinoma (HNSCC). We identified the large type IV intermediate filament (IF) protein, synemin [16-18] as a critical determinant of cellular radioresistance and NHEJ-related DSB repair in HSNCC. We mechanistically demonstrate that synemin governs DNA-PKcs phosphorylation and activity and reveal a fundamental role of synemin in DSB repair by serving as a kinase-anchoring protein for an ATM-dependent interaction with DNA-PKcs. Taken together, our study provides evidence of cytoarchitectural elements, such as intermediate filaments as key co-regulators of nuclear DNA repair.

\section{Results}

2.1. Identification of Adhesome-Based Key Regulators of Radiation Sensitivity and DNA Double Strand Break Repair in HNSCC

To systematically investigate the function of individual FAP in HNSCC radioresistance and DSB repair, we performed a high-throughput RNAi-based screen depleting 117 FAP in UTSCC15 HNSCC cells stably expressing EGFP-53BP1 (UTSCC15 EGFP-53BP1), as shown in Figure S1A,B, grown in 3D 1rECM (3DHT-RNAi-S), as shown in Figure 1A and Table S1. While a crucial contribution to cancer cell therapy resistance has been reported by us for several FAP, such as $\beta 1$ integrin, LIMS1, FAK and FHL2 [19-21], here we identified a number of novel candidates. In Figure 1B-D, we plotted the enhancement ratios of non-irradiated and irradiated cells, as well as the gain of EGFP-53BP1 foci, according to the formulas described under the Materials and Methods section. In the absence of irradiation, the colony formation capacity of UTSCC15-EGFP-53BP1 transfectants remained virtually unaffected. Exceptions for significantly induced colony formation were the depletion of, for example, fermitin family member 2 (FERMT2, also known as PLEKHC1) and zyxin and, for reduced colony formation, the depletion of kinesin family member 11 (KIF11), as shown in Figure 1B, Figures S2A and S3A and in Table S2. In contrast, colony formation capability was strongly altered with significant reductions upon the knockdown of several FAP, such as vinculin (VCL), growth factor receptor bound protein 7 (GRB7), sorbin and SH3 domain containing 2 (SORBS2) and synemin (SYNM), as shown in Figure 1C, Figures S2B and S3B and in Table S3. 
A

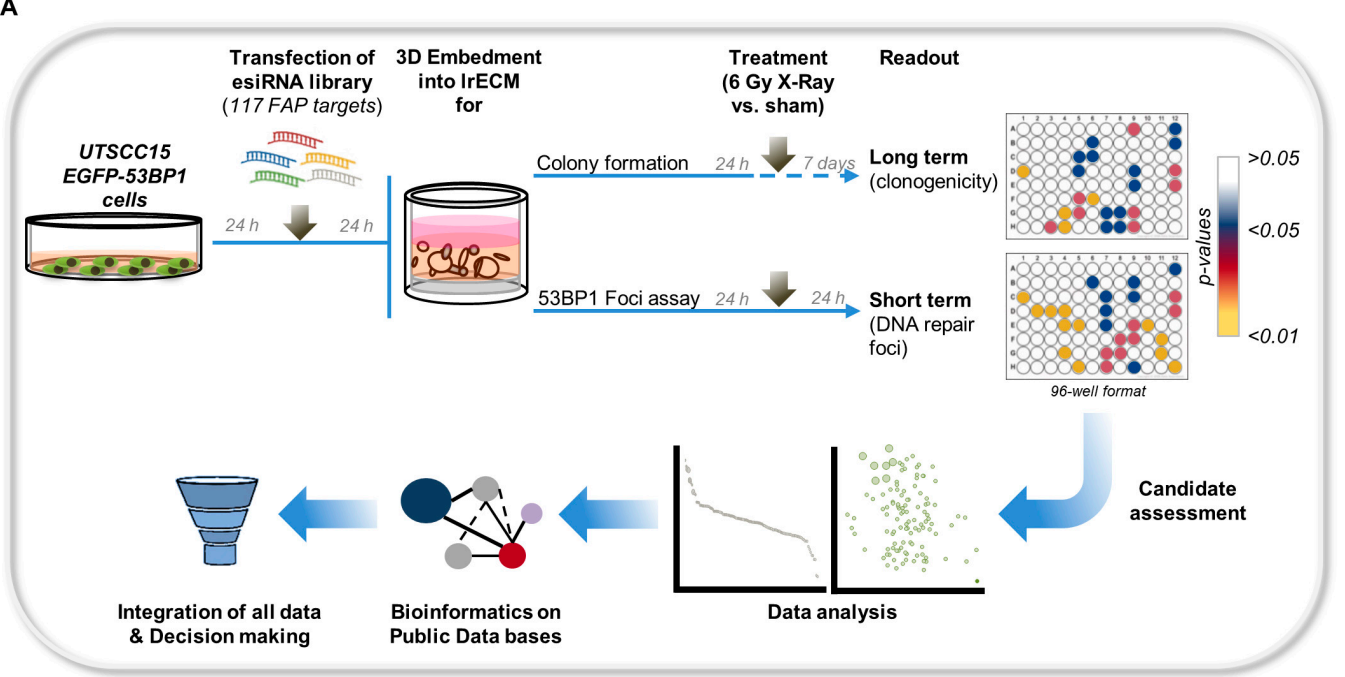

B

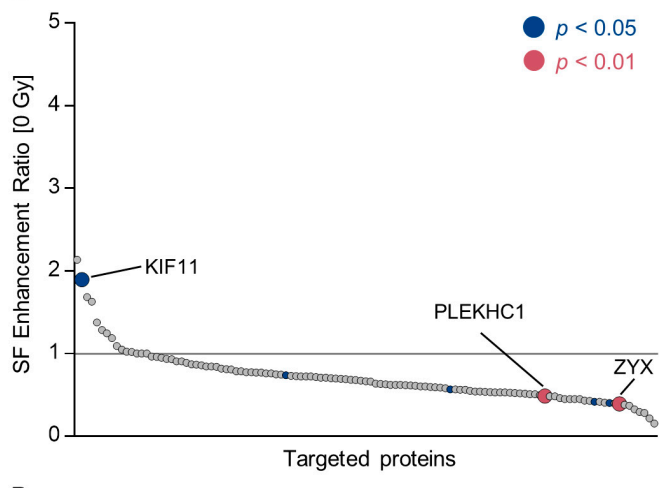

D

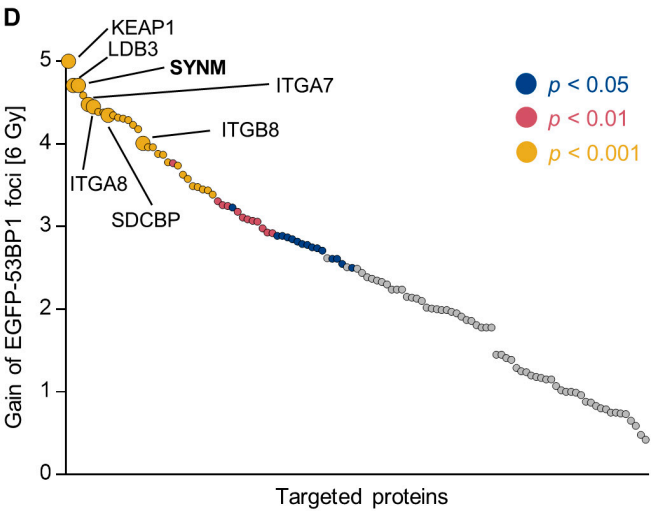

C

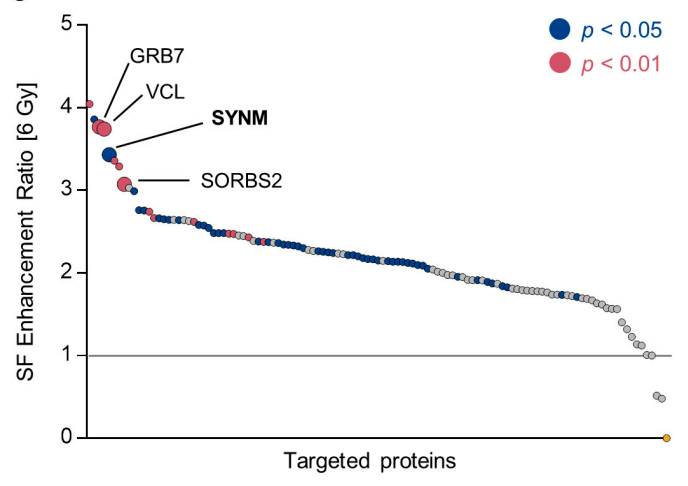

E

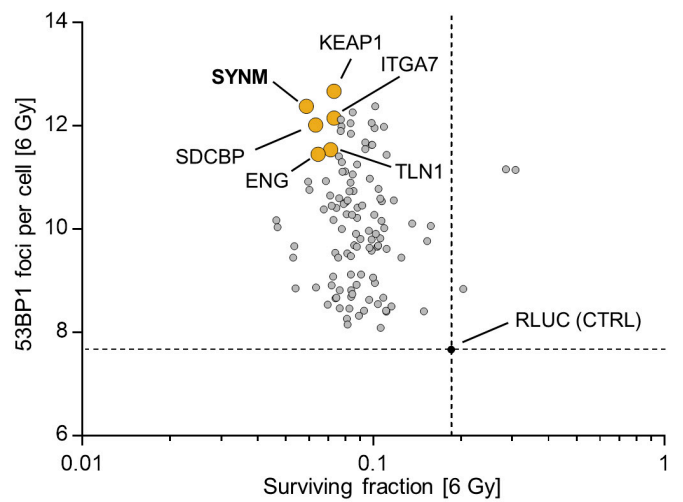

Figure 1. Identification of focal adhesion proteins affecting cell survival, radiosensitivity and DNA repair. (A) Workflow of 3D high-throughput RNAi screening (3D HTP-RNAi-S); (B) Surviving fraction-related enhancement ratios of EGFP-53BP1-expressing UTSCC15 cell cultures in response to focal adhesion protein (FAP) knockdowns $(n=4)$, the data and $p$-values for which are provided in Table S2; (C) Surviving fraction-related enhancement ratios of FAP knockdown cell cultures exposed to 6-Gy X-rays $(n=4)$, the data and $p$-values for which are provided in Table S3; (D) Gain of residual 53BP1 foci number per cell (24 h after irradiation) in FAP knockdown cell cultures irradiated with 6-Gy X-rays (53BP1 foci in controls were subtracted from the total number of foci) $(n=4)$; (E) Scatter plot displaying the relation between 53BP1 residual foci/cell and surviving fraction upon FAP knockdown and 6-Gy irradiation. Main selected candidates with high foci/cell and low cell survival are indicated. SF, surviving fraction; CTRL, control. 
In parallel, we quantified the residual EGFP-53BP1 foci as readout for DSB repair capacity in unirradiated and irradiated cell cultures. While basal levels of EGFP-53BP1 foci were unchanged, as shown in Figure S4A, the depletion of various FAP induced significant increases in residual EGFP-53BP1 foci, as shown in Figure 1D and Figure S4B. Novel identified determinants of DSB repair included the $\alpha 7, \alpha 8$, and $\beta 8$ integrin subunits, as well as kelch-like ECH associated protein 1 (KEAP1), talin 1, LIM domain binding 3 (LDB3), syndecan binding protein (SDCBP), and synemin, as shown in Figure 1D and Figure S4B. Plotting the surviving fraction at 6-Gy against gained 53BP1 foci numbers revealed, for some but not all proteins, a functional context between radiation survival and DSB repair, as shown in Figure 1E and Figure S5A,B. Taken together, our results imply that a perturbed function of specific FAP concurrently and significantly alters both colony formation and DSB repair. Moreover, the presented data show that our 3D-HT-RNAi-S is a robust screening platform for the identification of potential regulators of cellular radiation survival and DSB repair.

\subsection{Synemin Modulates Radiation Sensitivity and DNA Double Strand Break Repair in HNSCC Cells}

The novelty of these findings prompted us to focus our further analyses on one of the most promising candidates from our screen, the IF protein synemin. Using the Oncomine database (https://www.oncomine.org) [22], we explored synemin mRNA expression across multiple head and neck cancers and found that synemin was significantly upregulated in head and neck cancers compared to normal tissue, as shown in Figure 2A. In line with these data, synemin was amplified in several squamous cell carcinomas, such as HPV negative HNSCC, lung squamous cell carcinomas (LUSCC) and cervix squamous cell carcinomas (CESCC), as shown in Figure S6A. Next, we searched for the predicted protein interactions of synemin with the DNA repair machinery using Cytoscape [23] and identified a potential association of synemin with the DNA repair kinases ATM, ATR and DNA-PKcs, as shown in Figure S6B.

Subsequently, we sought to demonstrate that synemin acts as general determinant of both radiation survival and DSB repair. For this, we validated our 3D-HT-RNAi-S results in a panel of $103 \mathrm{D}$ lrECM grown HNSCC cell lines, which demonstrated synemin expression in both the cytoplasm and nucleus, as shown in Figure 2B,C and Figure S6C,D. Intriguingly, while basal colony formation remained unaffected, as shown in Figure 2D,F, all 10 HNSCC cell lines showed enhanced radiosensitivity upon synemin silencing, relative to the controls, as shown in Figure 2E,F. Accordingly, synemin silencing elicited significantly elevated 53BP1 foci numbers in all tested HNSCC cell lines after X-ray irradiation, relative to the controls, as shown in Figure 2G-I. Confirmatory data for the fundamental role of synemin in both radiation survival and DSB repair were generated in stably mCherry-Synemin-overexpressing SAS cells, as shown in Figure 2J. Synemin overexpression significantly increased colony formation ability and significantly lowered the numbers of residual EGFP-53BP1 foci, relative to the controls, as shown in Figure 2K,L, respectively. Collectively, our results suggest that synemin plays an essential role in cell survival, as well as in DSB repair after genotoxic injury. 


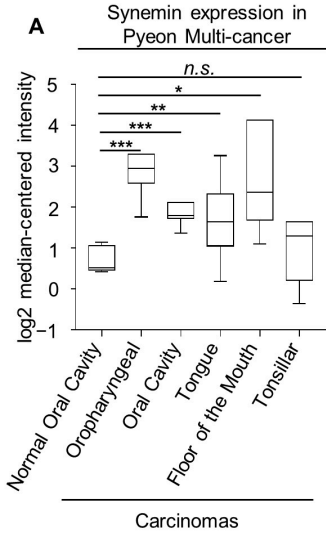

B
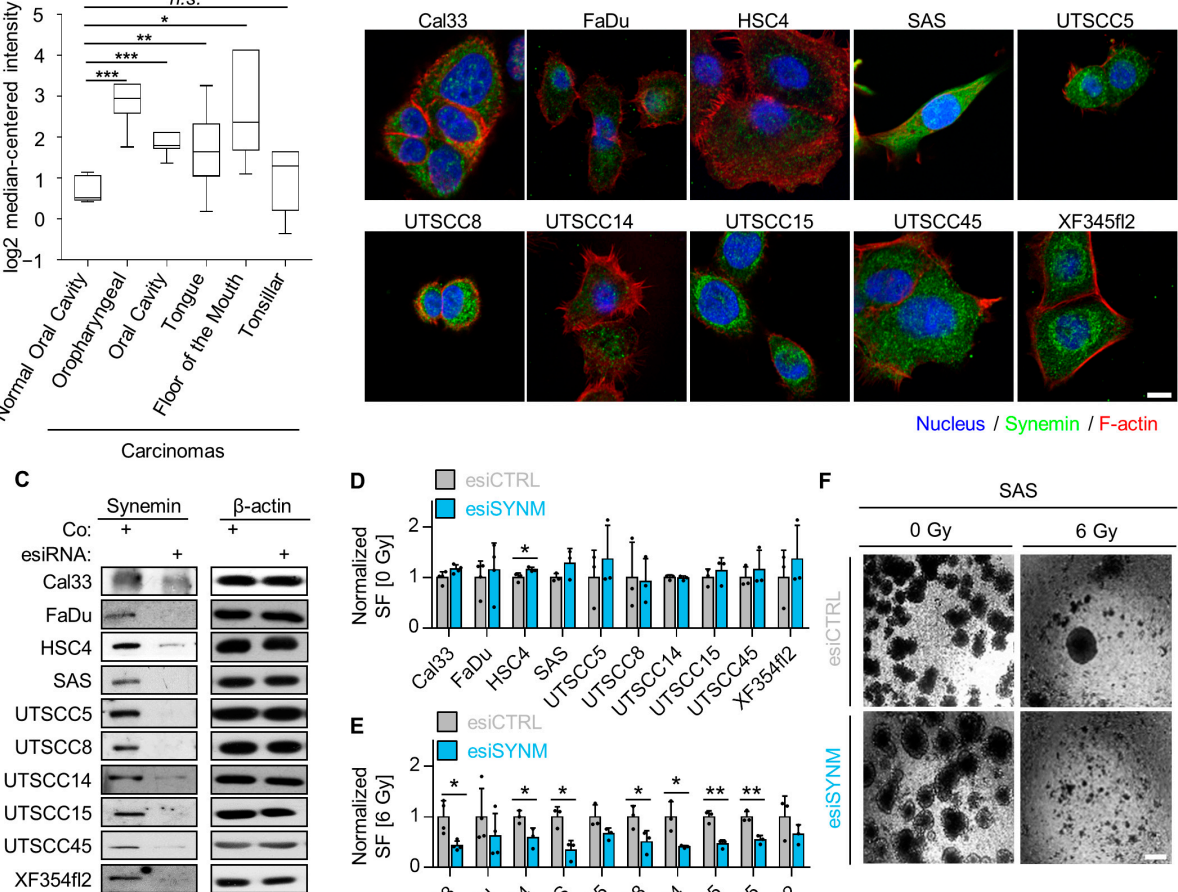

Nucleus / Synemin / F-actin
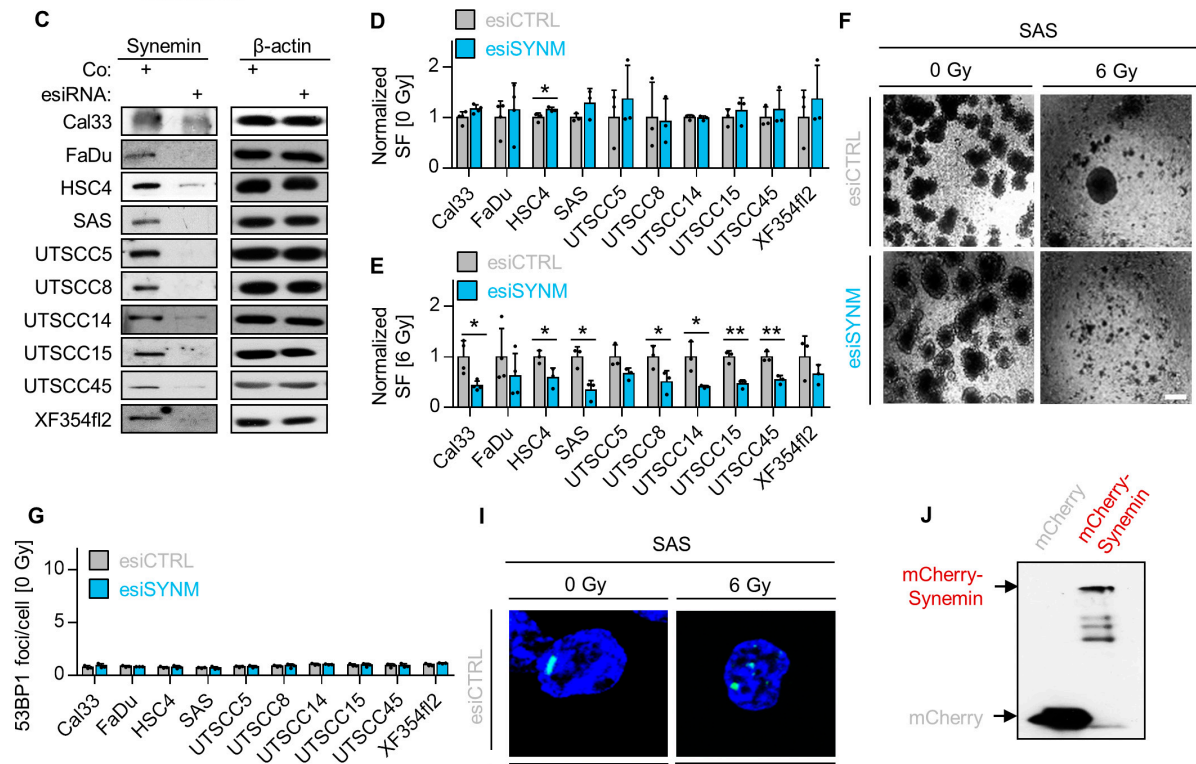

I
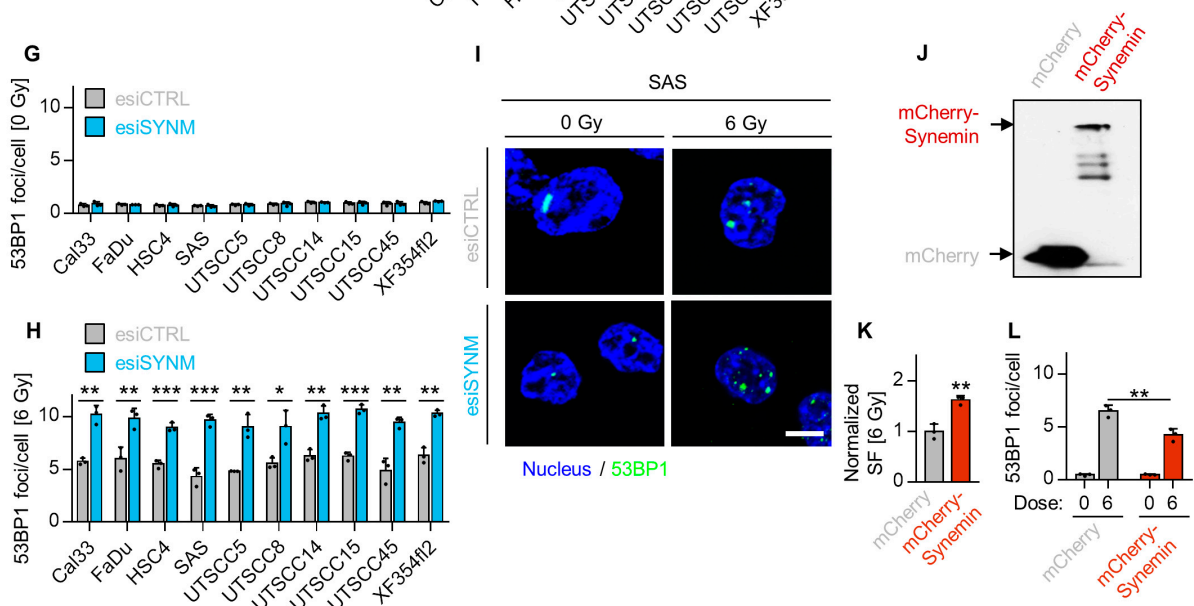

Figure 2. Synemin essentially controls radiosensitivity and DSB repair. (A) Analysis of synemin mRNA expression in head and neck carcinomas in comparison to corresponding normal tissue using Oncomine database; (B) Immunofluorescence staining of synemin distribution (green) in a panel of HNSCC cell lines. Cells were counterstained with Phalloidin (F-actin, red) and DAPI (nucleus, blue) (bar, $20 \mu \mathrm{m}$ ); (C) Immunoblots with knockdown efficiencies in a panel of HNSCC cell lines; (D) Normalized plating efficiency of a panel of HNSCC cell lines upon synemin inhibition $(n \geq 3)$; (E) Colony formation ability of 6-Gy X-ray irradiated 3D lrECM HNSCC cell cultures after esiRNA-mediated synemin depletion; (F) Representative phase contrast images of 3D lrECM SAS cell cultures (bar, $500 \mu \mathrm{m}$ ); (G) Spontaneous foci per cell in a panel of HNSCC cell lines upon synemin inhibition $(n=3)$; $(\mathbf{H})$ Effect of synemin silencing on residual 53BP1 foci (24 h after irradiation) in a panel of 6-Gy irradiated 3D lrECM HNSCC cell lines; (I) Representative immunofluorescence images of residual 53BP1 foci (bar, $10 \mu \mathrm{m})$; (J) Immunoblot of mCherry-Synemin and mCherry empty vector expression; (K) Colony formation ability of SAS mCherry-Synemin transfectants, relative to SAS mCherry controls (6-Gy X-rays); (L) Residual 53BP1 foci (24 h after irradiation) in SAS mCherry-Synemin transfectants exposed to 6-Gy X-rays. Data are presented as mean $\pm \mathrm{SD}\left(n=3\right.$; two-sided $t$-test; ${ }^{*} p<0.05,{ }^{* *} p<0.01$, *** $p<0.001)$. 


\subsection{Synemin Regulates NHEJ by Influencing DNA-PKcs and ATM Phosphorylation}

To unravel the role of synemin in DNA repair in more detail, we conducted DNA repair reporter assays to measure HR and NHEJ activities, as shown in Figure S7A. While synemin depletion left HR activity unaffected, NHEJ activity significantly declined by approximately $40 \%$, as shown in Figure $3 \mathrm{~A}, \mathrm{~B}$ and Figure S7B. In line, synemin overexpression resulted in a five-fold increase in NHEJ activity, as shown in Figure 3C. Subsequently, we examined the phosphorylation and expression of the key NHEJ-associated proteins, DNA-PKcs and ATM, and found that synemin silencing causes a defect in the radiogenic hyperphosphorylation of both DNA-PKcs at S2056 and ATM at S1981, as shown in Figure 3D,E, without affecting their basal expression levels, as shown in Figure S8A. In contrast, synemin overexpression enhanced basal and radiogenic levels of phosphorylated S2056-DNA-PKcs, as shown in Figure 3F,G. Next, we analyzed the kinetics of DNA-PKcs S2056, 53BP1 and $\gamma \mathrm{H} 2 \mathrm{AX}$ DNA repair foci upon 1-Gy X-ray irradiation in synemin-depleted cells and observed, in line with the reduced phosphorylation of DNA-PKcs, significantly declined DNA-PKcs S2056 foci levels over the $24 \mathrm{~h}$ observation period, relative to the controls, as shown in Figure $3 \mathrm{H}, \mathrm{K}$ and Figure S8B. In contrast, 53BP1 and $\gamma \mathrm{H} 2 \mathrm{AX}$ foci lacked a significant difference at $30 \mathrm{~min}$ post irradiation, but were significantly higher throughout the remaining observation time in the synemin-depleted cells, compared to the controls, as shown in Figure 3I,J and Figure S8B. Taken together, our data suggest that synemin critically modulates NHEJ by influencing DNA-PKcs and ATM.

\subsection{Synemin Influences DSB Repair Responses by Regulating DNA-PKcs}

Based on the observed dependency of DNA-PKcs phosphorylation on synemin and without significant differences in cell cycling, as shown in Figure S9, we next investigated the functional relationship between synemin and DNA-PKcs for DSB repair. Single and double depletion of synemin and DNA-PKcs intriguingly revealed similar residual 53BP1 and $\gamma \mathrm{H} 2 \mathrm{AX}$ foci numbers, relative to the controls after 6-Gy X-ray exposure, as shown in Figure 4A-C and Figure S10A,B. This suggests that: (i) synemin critically impacts on the functionality of DNA-PKcs in DSB repair; (ii) synemin and DNA-PKcs are components of the same signaling pathway. To underpin this interdependency of synemin and DNA-PKcs, we quantified colony formation after single and double knockdown without and in combination with irradiation. While basal cell survival was non-significantly affected, as shown in Figure 4D, single synemin and DNA-PKcs knockdown significantly enhanced cellular radiosensitivity, relative to the controls, as shown in Figure 4E. Intriguingly, both single DNA-PKcs, as well as double synemin/DNA-PKcs knockdown, induced radiosensitization to an extent superimposable to that observed for single synemin knockdown, as shown in Figure 4E. Thus, our results depict a dependency of the DNA damage response on a functional DNA-PKcs-synemin interaction. 

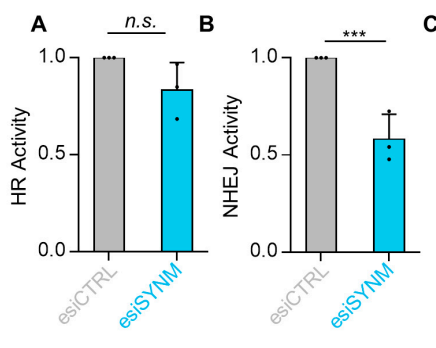

C
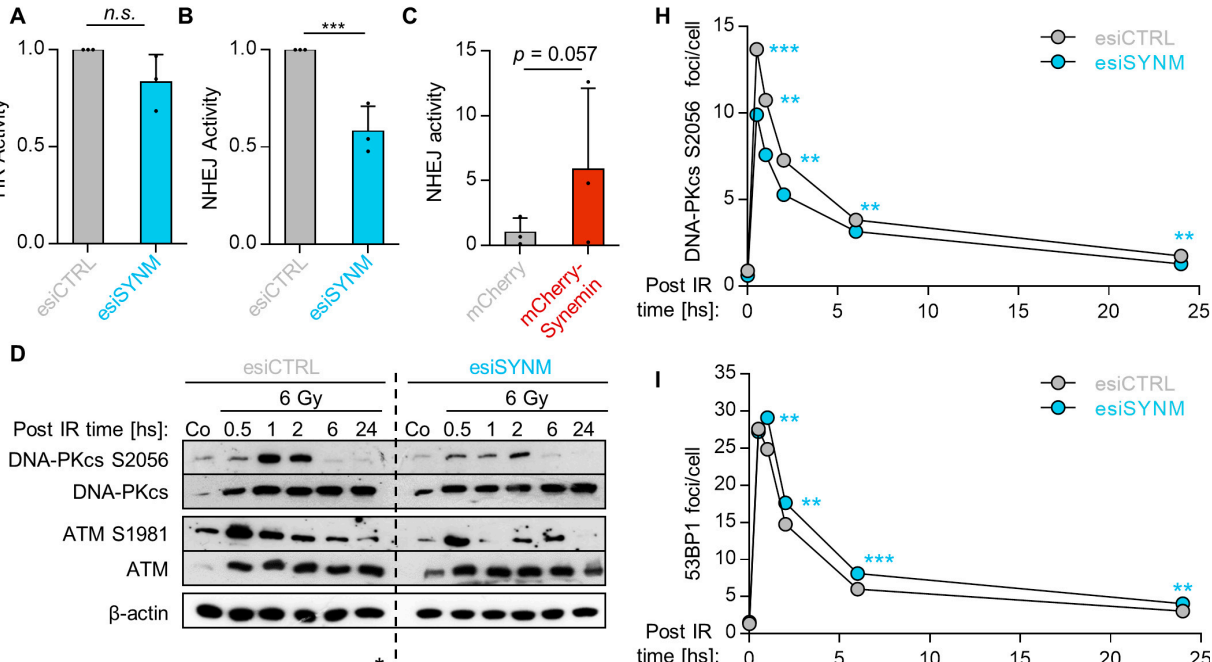

E

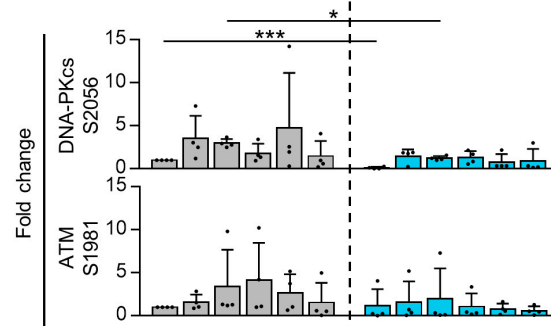

Post IR time [hs]: Co \begin{tabular}{lllllllllllll}
0.5 & 1 & 2 & 6 & 24 \\
\hline
\end{tabular} Co $\begin{array}{llllll}0.5 & 1 & 2 & 6 & 24\end{array}$

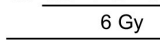

Gy
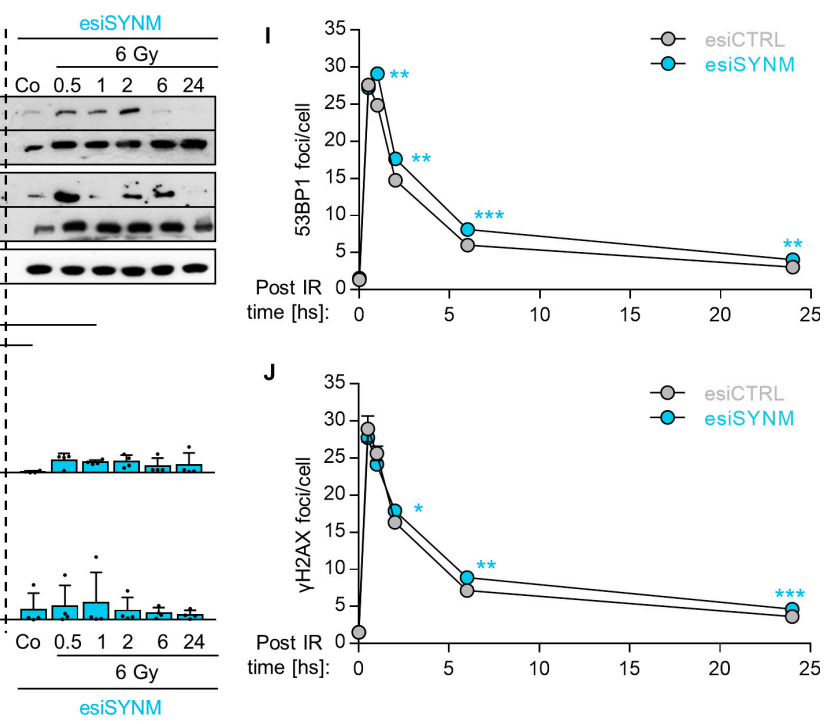

$\mathbf{F}$

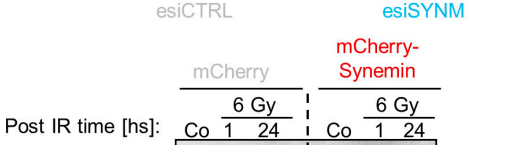

DNA-PKcs S2056

DNA-PKcs

$\beta$-actin

G

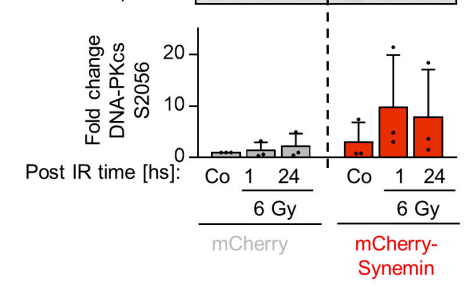

J

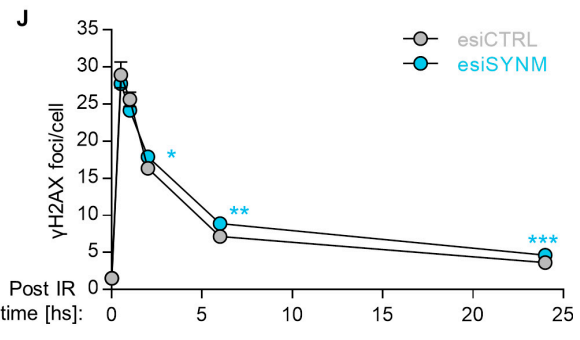

K
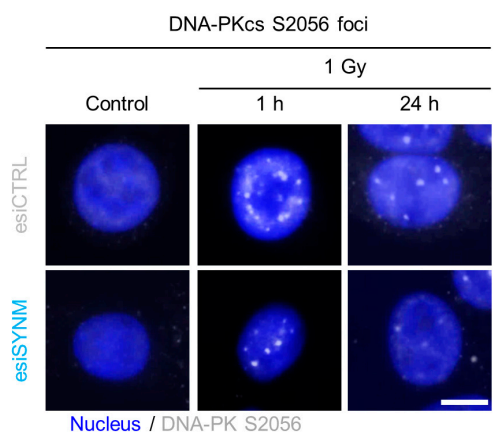

Figure 3. Synemin functions in non-homologous end joining. GFP-based reporter assays for (A) HR and (B) NHEJ. Cal33 cells stably transfected with DRGFP or pimEJ5GFP recombinant plasmids were depleted of synemin. The number of GFP-positive cells was analyzed by FACS, provided in Supplementary Figure S5A; (C) NHEJ activity in mCherry-Synemin-overexpressing Cal33-pEJ5GFP cells. Analysis performed by FACS as indicated under (A,B); (D,E) Immunoblots and fold changes from synemin-depleted and 6-Gy irradiated SAS cells showing total and/or phosphorylated forms of DNA-PKcs, ATM. $\beta$-actin served as loading control; (F,G) Immunoblot and fold change of DNA-PKcs from whole cell lysates of 6-Gy X-ray irradiated and mock-treated SAS mCherry-Synemin transfectants. $\beta$-actin served as loading control; (H-J) Kinetics of DNA-PKcs S2056, 53BP1 and $\gamma \mathrm{H} 2 \mathrm{AX}$ foci upon synemin knockdown at different time-points post 1-Gy X-rays in SAS cells; (K) Representative immunofluorescence images of residual DNA-PKcs S2056 foci of synemin knockdown and control cell cultures $1 \mathrm{~h}$ after 1-Gy X-rays (bar, $10 \mu \mathrm{m})$. Data are presented as mean $\pm \mathrm{SD}\left(n=3\right.$; two-sided $t$-test; ${ }^{* *} p<0.01{ }^{* * *} p<0.001$; n.s., not significant $(p \geq 0.05))$. 

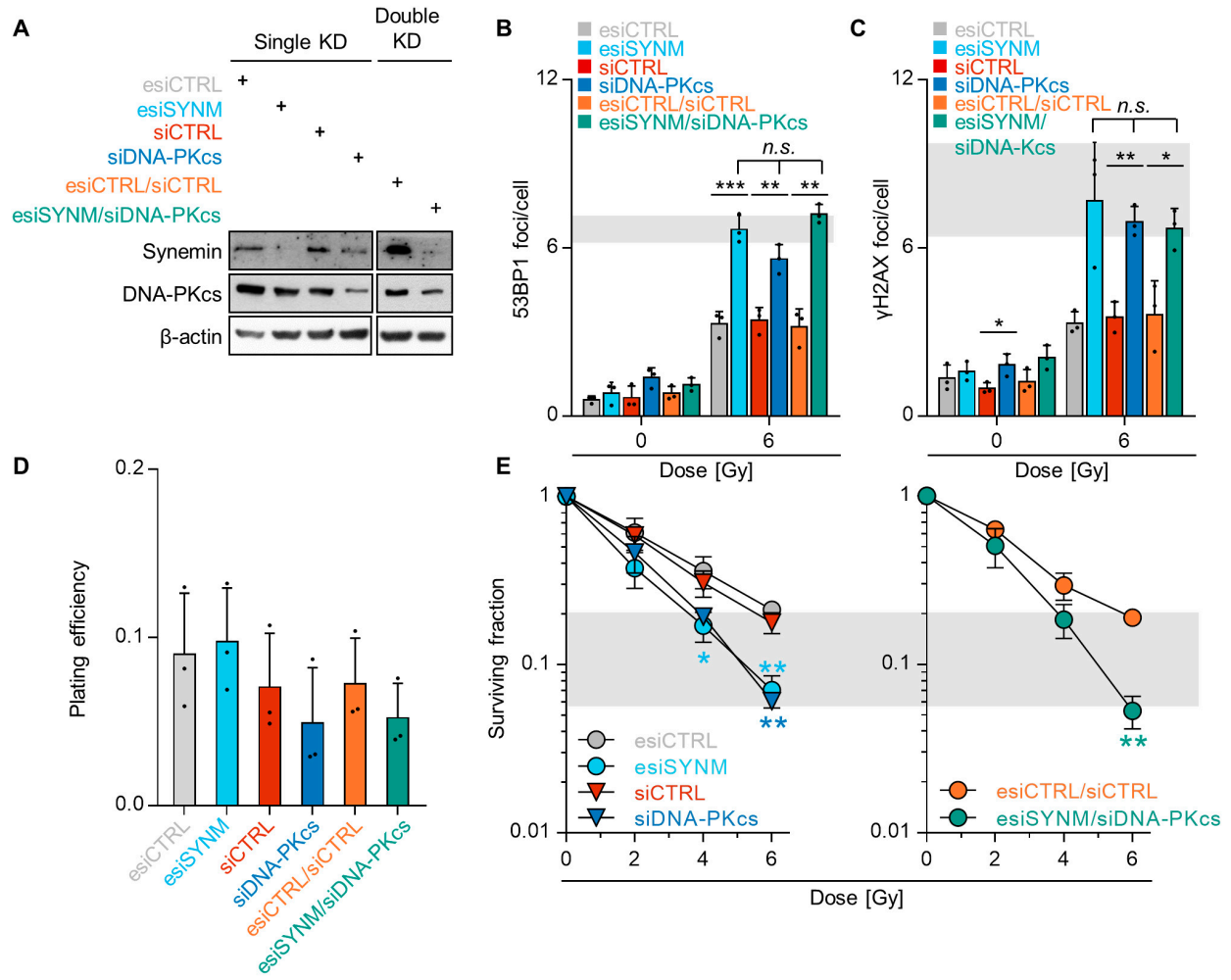

Figure 4. Synemin/DNA-PKcs co-control DSB repair and radiation survival. (A) Knockdown efficiencies of single and double esi/siRNA transfections of SAS cells. $\beta$-actin served as loading control; (B,C) Residual 53BP1 and $\gamma \mathrm{H} 2 \mathrm{AX}$ foci per cell (24 h after irradiation) upon single and double knockdown of synemin and DNA-PKcs in 6-Gy X-ray irradiated SAS cells. Transfection with single or double non-specific siRNA were used as controls; (D) Plating efficiency of SAS cells upon single and double knockdown of synemin and DNA-PKcs; (E) 3D colony formation ability upon single and double silencing of synemin and DNA-PKcs. Data are represented as mean \pm SD $(n=3$; two-sided t-test; ${ }^{*} p<0.05,{ }^{* *} p<0.01,{ }^{* * *} p<0.001$; n.s., not significant $\left.(p \geq 0.05)\right)$.

\subsection{Synemin Interacts with DNA-PKcs in an ATM-Dependent Manner}

To investigate a potential interaction between synemin and DNA-PKcs, we conducted immunoprecipitation (IP) assays with endogenous and mCherry-Synemin in unirradiated and X-ray irradiated SAS cells. In unirradiated cells, we found that DNA-PKcs bound to synemin, relative to the IgG and mCherry controls, as shown in Figure 5A,B (A = pulldown of endogenous synemin; $\mathrm{B}=$ pulldown of $\mathrm{mCherry-Synemin).} \mathrm{This} \mathrm{interaction,} \mathrm{however,} \mathrm{partially} \mathrm{dispersed} \mathrm{in} \mathrm{X-ray} \mathrm{irradiated}$ cells, as shown in Figure 5A,B. After observing a dependence of DNA-PKcs phosphorylation on synemin, we decided to perform a proximity ligation assay (PLA) between synemin and DNA-PKcs S2056, as shown in Figure S10C. Interestingly, we identified an interaction between synemin and the phosphorylated form of DNA-PKcs that was mainly nuclear, as shown in Figure S10D.

Based on our finding that not only DNA-PKcs, but also ATM, showed less radiogenic hyperphosphorylation, we hypothesized a putative interplay between synemin, DNA-PKcs and ATM. By means of SKX cells, a squamous cell carcinoma cell line with ATM downregulation by miR-421 overexpression [24], we show loss of DNA-PKcs pulldown in synemin immunoprecipitates from unirradiated and irradiated ATM-depleted SKX cells, as shown in Figure 5C in lanes 6 and 8, relative to the ATM-expressing SAS cells, as shown in Figure 5C in lanes 5 and 7. We further found an increased expression of synemin in SKX cells, suggesting a rescue or response mechanism elicited by ATM dysfunctionality, as shown in Figure 5C. To investigate the functional consequence of the synemin/DNA-PKcs interaction, we explored 53BP1 and DNA-PKcs S2056 DNA repair foci in unirradiated and irradiated mCherry- and mCherry-Synemin-expressing cells pretreated with the 
ATM inhibitor KU55933. Relative to DMSO-treated mCherry controls, 53BP1 and DNA-PKcs S2056 foci were significantly decreased at $1 \mathrm{~h}$ post irradiation and significantly increased at $24 \mathrm{~h}$ post 1-Gy irradiation in the KU55933-pretreated mCherry controls, as shown in Figure 5D,E. Importantly, a similar pattern was found in mCherry-Synemin-expressing cells, as shown in Figure 5D,E. Hence, our results show that the general function of synemin in DSB repair and the recruitment of 53BP1 and DNA-PKcs to DSBs is ATM-dependent.
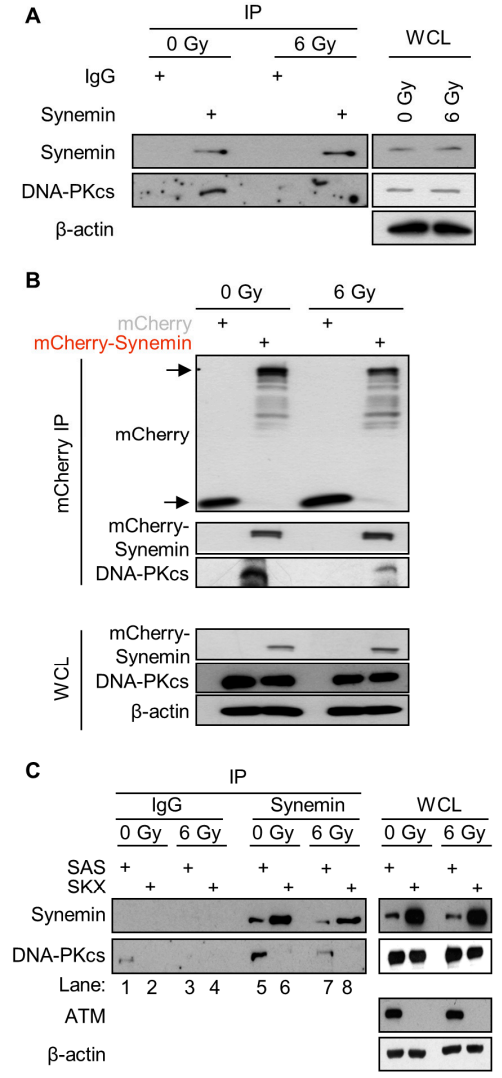

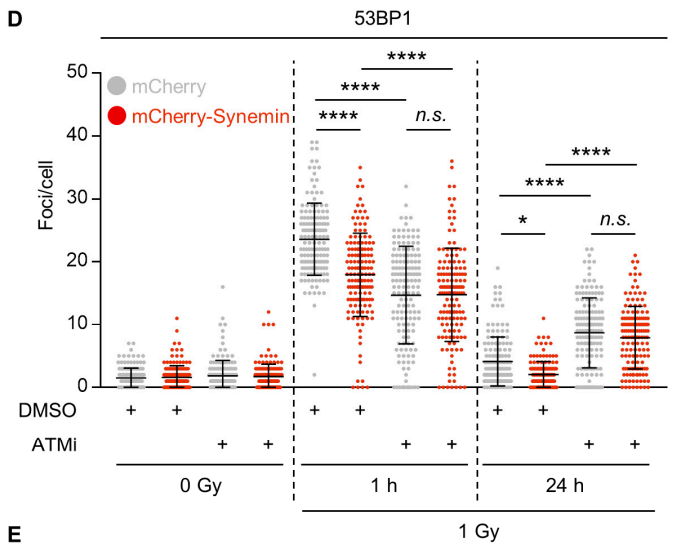

E

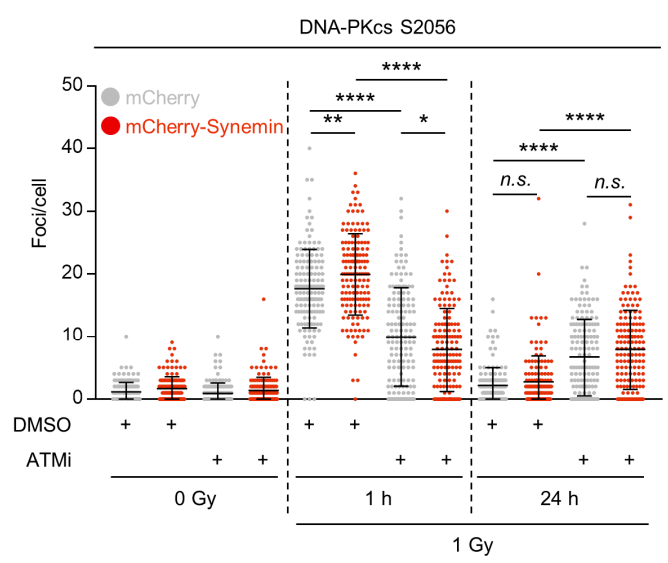

Figure 5. DNA-PKcs directly interacts with synemin and depends on ATM activity. (A) Immunoprecipitation (IP) of Synemin $1 \mathrm{~h}$ post 6-Gy X-rays. Western blot analysis showing expression of Synemin and DNA-PKcs in immunoprecipiates and whole cell lysates (WCL) from SAS cells; (B) Western blot on mCherry immunoprecipitates from 6-Gy irradiated mCherry-SAS and mCherry-Synemin-SAS cells at $1 \mathrm{~h}$ post irradiation. $\beta$-actin served as loading control; (C) Western blots on synemin immunoprecipitates from SAS and SKX cells $1 \mathrm{~h}$ after 6-Gy X-ray exposure; (D,E) 53BP1 and DNA-PKcs S2056 foci upon ATMi treatment (DMSO used as control) at different time points post 1-Gy X-rays in SAS mCherry and mCherry-Synemin transfectants. Data are represented as mean $\pm \mathrm{SD}\left(n=3\right.$; One-way ANOVA followed by post hoc test (Tukey multiple comparisons); ${ }^{*} p<0.05$, ${ }^{* *} p<0.01,{ }^{* * *} p<0.001,{ }^{* * * *} p<0.0001$; n.s., not significant $\left.(p \geq 0.05)\right)$.

\subsection{ATM Phosphorylation of the Synemin Tail Modulates DNA Repair}

To determine the part of the synemin protein mediating its function in DNA repair, we generated two synemin constructs-one by the deletion of coil-coil linker/tail domains (mCherry-Synemin_Head) and another one by the deletion of head/coil-coil linker domains (mCherry-Synemin_Tail), as shown in Figure 6A and Figure S11A. We evaluated 53BP1 and DNA-PKcs S2056 DNA repair foci upon the overexpression of full-length mCherry-Synemin and the deletion variants. We found reduced 53BP1 and increased DNA-PKcs S2056 foci numbers in mCherry-Synemin-overexpressing cells, as shown in Figure 6B,C, respectively. Interestingly, these effects were lost upon the expression of mCherry-Synemin_Head, but not mCherry-Synemin_Tail, as shown in Figure 6B,C, respectively, 
suggesting the tail of synemin to be key for synemin's function in DNA repair. Furthermore, the observed overexpression effects of synemin on residual 53BP1 foci were lost post 1-Gy X-ray exposure upon pretreatment with KU55933 indicating a dependency of the function of the synemin tail domain on ATM activity, as shown in Figure 6D.

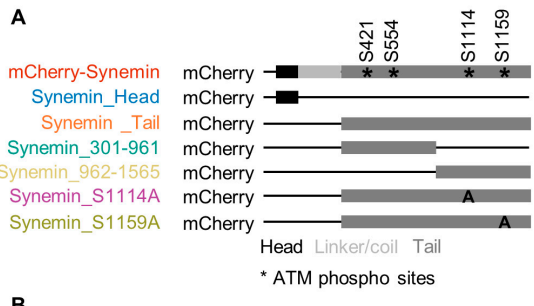

B

53BP1
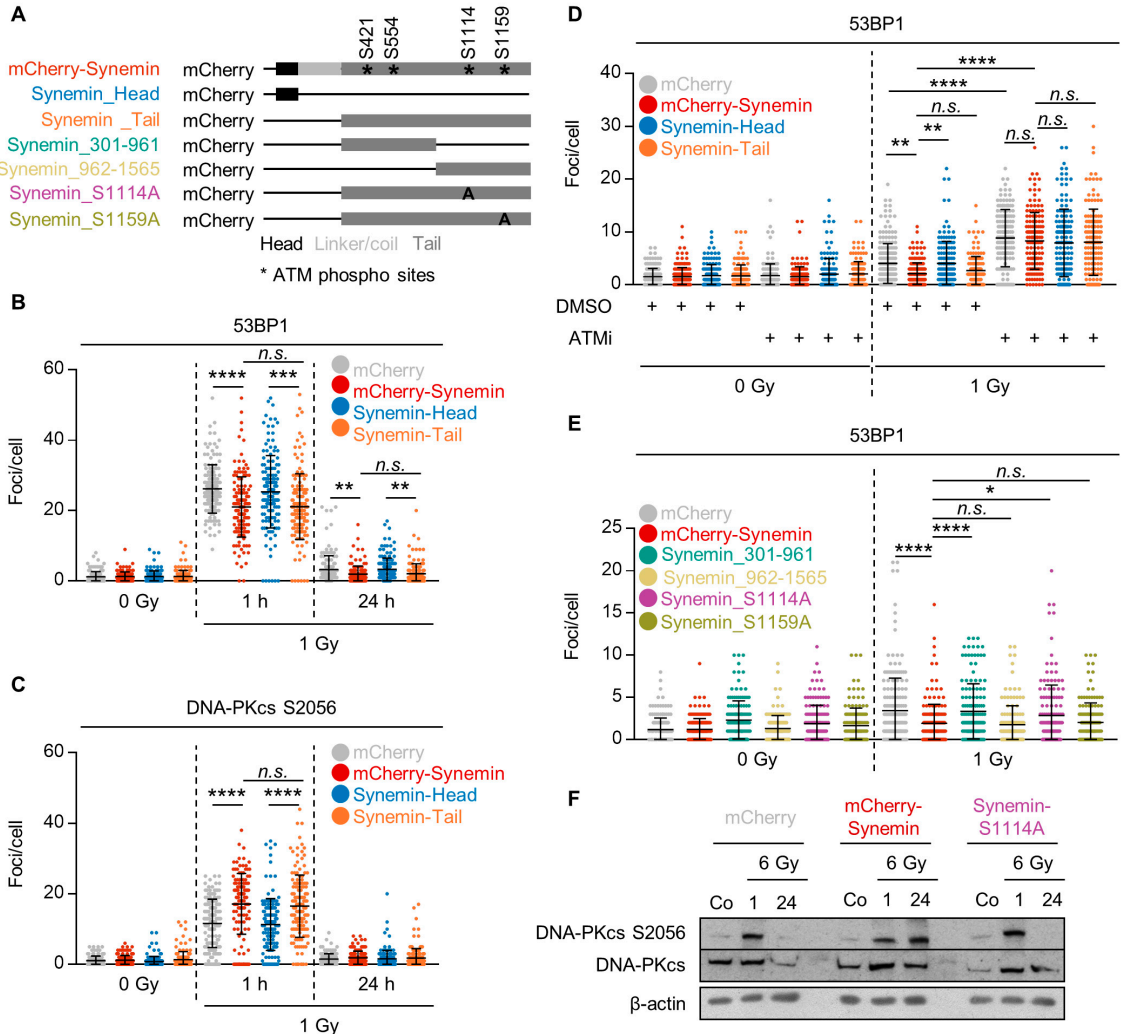

E
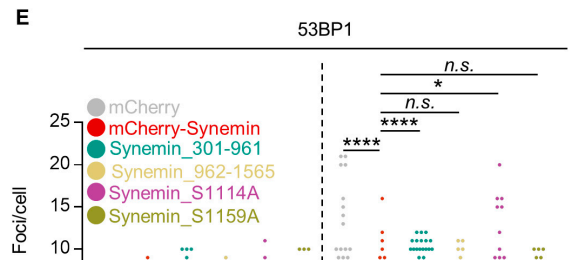

\begin{tabular}{ll}
\hline$\overline{0}$ & 15 \\
\hline & 10
\end{tabular}

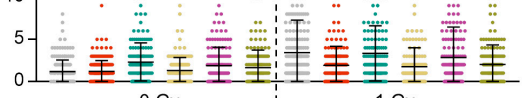

F

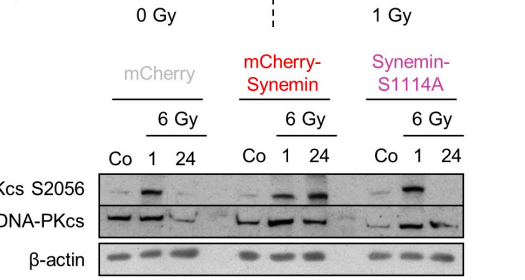

G
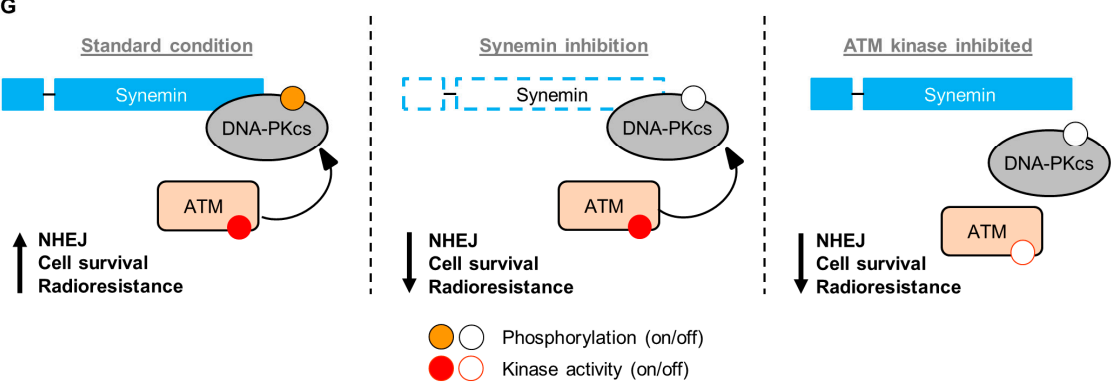

Figure 6. Synemin-mediated DNA repair depends on the S1114 phosphorylation site of synemin. (A) Design of different synemin constructs; (B,C) 53BP1 and DNA-PKcs S2056 foci kinetics in 1-Gy $\mathrm{X}$-ray-irradiated SAS cells expressing mCherry-Synemin wildtype, mCherry-Synemin_Head or mCherry-Synemin_Tail (mCherry was used as control); (D) Residual 53BP1 foci (24 h after irradiation) in SAS cells expressing mCherry-Synemin wildtype, mCherry-Synemin_Head or mCherry-Synemin_Tail (mCherry was used as control) treated with ATMi and 1-Gy X-rays; (E) Residual 53BP1 foci (24 h after irradiation) in 1-Gy X-ray-irradiated SAS transfectants expressing mCherry-Synemin wildtype, mCherry-Synemin_301-961, mCherry-Synemin_962-1565, mCherry-Synemin_S1114A and mCherry-Synemin_S1159A (mCherry was used as control); (F) Western blotting of lysates from 6-Gy irradiated ( 1 and $24 \mathrm{~h}$ ) and unirradiated SAS cells expressing mCherry, synemin-wt and synemin-S1114A; (G) Schematic depiction of how synemin interacts with DNA-PKcs and ATM for controlling NHEJ, cell survival and radioresistance in HNSCC cells, and that either synemin or ATM targeting renders cells equally radiosensitive. Results are presented as mean $\pm \mathrm{SD}(n=3$; One-way ANOVA followed by post hoc test (Tukey multiple comparisons); ${ }^{*} p<0.05,{ }^{* *} p<0.01,{ }^{* * *} p<0.001,{ }^{* * *} p<0.0001$; n.s., not significant $(p \geq 0.05))$. 
In order to predict the amino acid residues phosphorylatable by ATM, we used the GSP database and found the S421, S554, S1114 and S1159 amino acid residues at the synemin tail, but none at the head or coil-linker domains of synemin. To characterize the role of these phosphorylation sites at the synemin tail for DNA repair, we generated further synemin constructs containing either tail amino acids 301 to 961 (mCherry-Synemin_301-961) or tail amino acids 962 to 1565 (mCherry-Synemin_962-1565), as shown in Figure 6A and Figure S11B. The analysis of 53BP1 repair foci upon 1-Gy X-ray irradiation revealed a significant increase in 53BP1 foci in cells expressing mCherry-Synemin_962-1565, but not mCherry-Synemin_301-961, indicating a potential engagement of S1114 and S1159 in DNA repair, as shown in Figure 6C,D. To further prove the functionality of these serine residues, we introduced point mutations preventing the phosphorylation of either S1114 (mCherry-Synemin_S1114A) or S1159 (mCherry-Synemin_S1159A), as shown in Figure 6A and Figure S11B,C. Additionally, 53BP1 foci quantification upon the overexpression of these constructs revealed that S1114, but not S1159, is essential for the repair of radiogenic DSBs, as shown in Figure 6E and Figure S11C.

Subsequently, we explored the phosphorylation kinetics of DNA-PKcs S2056 in mCherry controls, mCherry-Synemin transfectants and mCherry-Synemin S1114A mutants upon 6-Gy X-ray exposure. Intriguingly, the serine 1114 point mutation led to a similar phosphorylation kinetic than mCherry controls, while mCherry-Synemin expression conserved DNA-PKcs phosphorylation over the 24-h observation period, as shown in Figure 6F. These data evidently show that the serine 1114 amino acid residue at the synemin tail is specifically required for its DNA repair function. Interestingly, this serine is surrounded by glutamines $(Q)$ indicating that the amino acid residue sequence from 1113 to 1115 is QSQ, for which a higher specificity for ATM phosphorylation has been documented [25]. Taken together, our study shows that the ATM-dependent interaction of synemin and DNA-PKcs controls NHEJ, cell survival and radiosensitivity. Synemin silencing perturbs DNA-PKcs phosphorylation, reduces cell survival and enhances radiosensitivity by modulating the functionality of NHEJ, as shown in Figure 6G.

\section{Discussion}

The reduction in treatment resistance remains one of the major challenges for improving cancer patient survival. To safeguard genomic stability and survival, normal and transformed cells employ multiple efficient and complex DNA repair mechanisms. While numerous DNA-damaging agents like radio- and chemotherapy are standard of clinical care, the addition of biologicals seems required and advantageous for a more efficacious eradication of the various subpopulations of therapy-sensitive and -resistant malignant cells. Recent work has demonstrated that the two main DNA repair processes (i.e., HR and NHEJ), are more than just nuclear events as they are critically co-regulated by extracellular and cytoplasmic cues [26,27]. Among these factors, numerous transmembrane growth factor and adhesion receptors, as well as cytoplasmic protein kinases and adapter proteins coalescing at focal adhesions, exist. These focal adhesions serve as essential and powerful hubs for pro-survival resistance-mediating and DNA repair-modifying signal transduction $[8,11,26,28-31]$. To gain deeper insight into the functions of focal adhesion proteins (FAP) in the therapy resistance of HNSCC cancer cells, we established a 3D high-throughput RNAi-based screen (3DHT-RNAi-S) and identified a previously uncharacterized function of the IF protein, synemin. We show that synemin regulates the auto-phosphorylation of DNA-PKcs (S2056) and the recruitment of DNA-PKcs to DSB for modulating NHEJ and the radiochemosensitization of HNSCC cells, as shown in Figure 6G.

The type IV IF protein synemin, expressed as an alpha and a beta form, is critical for various cell functions and the formation of organs, such as heart and bones [16,32]. Similar to other IF proteins, synemin is overexpressed in different human malignancies, contributing to a more aggressive phenotype [33,34]. In breast cancer, synemin expression is modified by aberrant promoter methylation and correlates with early relapse [35]. In glioblastoma, synemin controls cell proliferation through AKT by antagonizing PP2A [36]. Interestingly, in human hepatocellular carcinomas, a down-regulation of synemin fails to alter the stability of the cytoskeleton, indicating the tissue specificity and 
multifunctionality of synemin [37]. In line with our findings of a synemin-DNA-PKcs interaction, synemin has been described as an IF protein with an inability to self-assemble into filaments [38]. In turn, these unique biophysical properties of synemin facilitate the assembly of dynamic and content-specific cytoarchitecture- and stress response-related interactomes [39]. The involvement of IF in the cellular stress response is well known for various challenging events, such as tissue repair, heat shock, antimicrobial defense and apoptosis [40,41]. Our observations widen this spectrum to a new facet (i.e., DNA repair upon radiogenic genotoxic stress). Obviously, the cellular response to damaged DNA and the processes required for genome protection and integrity are among a number of commonalities between these stress conditions. It is of utmost interest that the more widely active and error-prone NHEJ repair mechanism seems to be controlled by an IF protein that also forms a protein complex with the essential DNA repair protein, DNA-PKcs. Moreover, our data pinpoint that synemin lies hierarchically upstream of DNA-PKcs. These findings might be contextually linked to coordinated actions between cytoskeletal elements and the DNA found during cell movement and cell division. IF proteins, similar to actin filaments or microtubules, liaise cell membrane and nuclear membrane/envelope through the Linker of the Nucleoskeleton and Cytoskeleton (LINC) complexes [42,43]. This allows evolutionary conserved processes to be conducted, such as transfer of physical forces from the extracellular space onto chromosomes or the cytoplasmic-nuclear transfer of IF proteins. In line with our data, Lottersberger and colleagues noted the dependence of telomeres on the LINC complex, microtubules and 53BP1 [44]. They proposed that increased telomere mobility induces NHEJ and reduces mis-repair through an increased probability for correct ligations.

Another influencing facet is the dependency of the synemin-DNA-PKcs protein complex formation on ATM kinase activity in the absence and presence of radiogenic genotoxic injury. Additionally and irrespective of its kinase activity, DNA-PKcs dispersed from synemin in a radiogenic stress-dependent manner. Using the ATM deficient cell line SKX, we provide evidence that the interrelation between DNA-PKcs and synemin relies on ATM. GPS database computational prediction of phosphorylatable amino acid residues of the synemin tail yielded several potential substrates for ATM, which essentially contribute to DSB repair in an ATM-dependent manner. This result is not very surprising on the basis of ATM's multiple roles, such as DSB detection and repair, global DNA damage checkpoint activation and the organization of the local and the global chromatin landscape [45]. In addition, it was recently shown that mitochondria exchange and survival and DNA repair signaling is rigorously ATM-dependent under multicellular conditions [46]. In view of our findings, ATM seems localized upstream of a regulatory synemin-DNA-PKcs complex, acting as a superior determinant of DSB repair.

In summary, our results reveal a critical function of the IF protein, synemin in regulating the radiosensitivity of HNSCC cells through the modulation of NHEJ-mediated DSB repair. In an ATM-dependent manner, synemin serves as a scaffold for DNA-PKcs and co-determines DSB repair upon genotoxic injury. Our findings further highlight the complexity of DSB repair by supporting the concept of cytoarchitectural elements as key co-regulators of nuclear events, such as the DNA damage response.

\section{Materials and Methods}

\subsection{Cell Lines and 3D Cell Culture}

HNSCC cell lines (Cal33, FaDu, SAS, UTSCC5, UTSCC8, UTSCC14, UTSCC15, UTSCC45 and XF354fl2) were kindly provided by R. Grenman (Turku University Central Hospital, Turku, Finland). SKX cells were kindly provided by M. Krause (Technische Universität Dresden, Dresden, Germany). Cal33-DRGFP and Cal33-pimEJ5GFP were kindly provided by K. Borgmann (University Medical Center Hamburg-Eppendorf, Hamburg, Germany). Cells were asynchronously grown in Dulbecco's modified Eagle's medium containing glutamax-I (from AppliChem, Darmstadt, Germany) supplemented with $10 \%$ fetal calf serum and $1 \%$ non-essential amino acids (all PAA Laboratories, Toronto, ON, Canada) at $37^{\circ} \mathrm{C}$ in a humidified atmosphere containing $8.5 \% \mathrm{CO}_{2}$. For $3 \mathrm{D}$ cell cultures, cells were embedded 
in $0.5 \mathrm{mg} / \mathrm{mL}$ laminin-rich extracellular matrix (lrECM) (Matrigel; BD, Heidelberg, Germany), as described previously [21]. All cell lines were authenticated using STR DNA profiling and tested negative for mycoplasma contamination.

\subsection{X-Ray Irradiation}

Irradiation was performed at room temperature using single doses of $200 \mathrm{kV}$ X-rays (Yxlon Y.TU 320; Yxlon, Hamburg, Germany; dose rate $1.3 \mathrm{~Gy} / \mathrm{min}$ at $20 \mathrm{~mA}$ ), filtered with $0.5 \mathrm{~mm} \mathrm{Cu}$, as described previously [47]. Dosimetry for quality assurance was performed using a Duplex dosimeter (PTW Freiburg; Freiburg, Germany) prior to irradiation.

\subsection{Antibodies}

Specific primary and secondary antibodies and their purchasing source are listed in Tables S4 and S5 in the Supplementary Materials and Methods.

\subsection{D High-Throughput Screen Using esiRNA (3D HTP-RNAi-S)}

We designed a 3D HTP-RNAi-S library of endoribonuclease-prepared siRNAs (esiRNA) [48] for 117 focal adhesion proteins and control esiRNA, as noted in Supplementary Table S1, based on [49]. The library was purchased from Eupheria Biotech (Dresden, Germany). UTSCC15 cells stably expressing pEGFP-53BP1-C1 were seeded in 96-well plates and were transfected for $8 \mathrm{~h}$ using a solution composed of $18.6 \mu \mathrm{L}$ Opti-MEM, $1 \mu \mathrm{L}$ esiRNA (concentration, $10 \mathrm{ng} / \mathrm{mL}$ ) and $0.4 \mu \mathrm{L}$ oligofectamine (Invitrogen, Karlsruhe, Germany) per well. Subsequently, Opti-MEM plus 10\% FCS was added to the cells. After $24 \mathrm{~h}$ the cells were re-suspended in $0.5 \mathrm{mg} / \mathrm{mL} \mathrm{lrECM}$ and seeded in 96-well plates, pre-coated with $1 \%$ agarose. The next day, cells were irradiated with $6-G y \mathrm{X}$-rays or left untreated. The residual number of foci was evaluated $24 \mathrm{~h}$ post irradiation, while colony formation ability was measured after eight days of incubation, as published in [11]. Enhancement ratios (ER) were calculated as follows:

$$
\text { ER }(0 \text { or } 6)=\frac{\sum \text { Normalized surviving fraction esiCTRL }}{\sum \text { Normalized surviving fraction esiRNA }}
$$

The residual foci number was calculated by subtracting the number of the esiCTRL foci to the esiRNA treated cells post 6-Gy X-ray.

\section{5. esiRNA and siRNA Transfection}

Synemin esiRNA (comprised of a heterogeneous pool of siRNA) was purchased from Eupheria Biotech. DNA-PKcs siRNA and Silencer Negative Control siRNA (AM4635) were obtained from Ambion (Darmstadt, Germany). All the esi/siRNA sequences are listed in Table S6 in Supplementary Materials and Methods. siRNA transfection was carried out as published in [11]. In brief, $24 \mathrm{~h}$ after plating, $26 \mathrm{nM} / 20 \mathrm{nM}$ esiRNA/siRNA was delivered using $8 \mu \mathrm{L}$ and $4 \mu \mathrm{L}$ oligofectamine, respectively, and Opti-MEM (Invitrogen) under serum-free condition for $8 \mathrm{~h}$. Subsequently, Opti-MEM plus 10\% FCS was added to the cells. Twenty-four hours post transfection, the cells were used for performing DNA DSB and colony formation assays.

\subsection{Total Protein Extraction, Western Blotting}

Twenty-four hours after transfection with esiRNA (esiCTRL and esiSYNM), the cells were re-seeded in 3D lrECM. The next day, the cells were irradiated with 6-Gy X-rays or left unirradiated. The harvesting of total cell lysates was performed after $0.5,1,2,6$ or $24 \mathrm{~h}$ post irradiation. Whole cell lysates, SDS-PAGE and Western blotting were performed, as previously described in [11]. Original uncropped image of Western Blot can be found at Figure S11. 


\subsection{D Colony Formation Assay}

The 3D colony formation assay was applied for measuring the ability of a single cell to form a colony, as published in [11]. The cells were transfected with esiRNA/siRNA (see esiRNA and siRNA transfection) and the next day were embedded into $0.5 \mathrm{mg} / \mathrm{mL} 1 \mathrm{rECM}$ in 96 -well plates. The cells were irradiated $24 \mathrm{~h}$ post reseeding and kept for several days (cell line-dependently) in $8.5 \% \mathrm{CO}_{2}$ at $37^{\circ} \mathrm{C}$. Each point on the survival curve represents the mean surviving fraction from at least three independent experiments.

\subsection{Foci Assay}

For determination of DSBs, cells were stained for $\gamma \mathrm{H} 2 \mathrm{AX}$ and 53BP1, as described in [11]. Further details can be found in Supplementary Materials and Methods.

\subsection{Synenim Constructs and Stable Transfection}

Human mCherry-Synemin was kindly provided by R. J. Bloch (University of Maryland, College Park, MD, USA). Different constructs were generated using PCR. The set of primers can be found in Table S7 in Supplementary Materials and Methods. The primers used for the generation of all the constructs were designed with the HindIII restriction site for the forward primer and the BamHI restriction site for the reverse primer. Synemin putative phosphorylation sites were mutated using QuickChangeII XL Site directed Mutagenesis (\#33790, Agilent, Santa Clara, CA, USA) by modifying one or two residues. The primers used for each mutation are listed in the Supplementary Methods. The mutated sites were confirmed by sequencing. Stable transfection of the synemin constructs was performed as published in [47] using lipofectamine2000 (Invitrogen) and G418 (\#A1720, Sigma-Aldrich, Taufkirchen, Germany) for the selection of cells.

\subsection{DRGFP and pimEJ5GFP-Based Chromosomal Break Reporter Assay}

For measuring HR and NHEJ activity, DRGFP and pimEJ5GFP plasmids were stably transfected, respectively, to generate an isogenic cell line pair (Cal33), as published in [50]. To measure HR/NHEJ-mediated repair, the cells were transiently transfected with pcDNA3BMyc-NLS-ISceI to express the I-SceI endonuclease for DSB induction [51]. Along with I-SceI, the pEGFP-N1 plasmid (Clontech, Mountain View, CA, USA), was transfected for determining transfection rates. Transfection was performed using lipofectamine2000. At $8 \mathrm{~h}$ after esiRNA transfection, the cells were transfected with I-SceI and pN1 plasmids. Four hours thereafter, the cells were trypsinized and embedded into $0.5 \mathrm{mg} / \mathrm{mL} \mathrm{lrECM}$. In the case of Synemin overexpression (mCherry-Synemin and mCherry-C1), both plasmids were transfected together with the pN1 and I-SceI. Transfection was performed using lipofectamine2000, according to the manufacturer's protocol. The cells were then reseeded in 3D, trypzinized at $72 \mathrm{~h}$ and subjected to flow cytometry (FACS Canto; BD Biosciences, San Jose, CA, USA). Per sample, $2 \times 10^{4}$ events were measured. GFP-positive cells were normalized to pEGFP-N1-positive cells and analysis was performed using FlowJo software (version 7.6.2; BD, San Jose, CA, USA).

\subsection{Proximity Ligation Assay (PLA)}

PLA was performed according to the manufacturer's protocol using the Duolink ${ }^{\circledR}$ PLA protein detection kit with PLA PLUS and MINUS Probes for mouse and rabbit (DUO92101-1KT, Sigma-Aldrich). More details can be found in Supplementary Materials and Methods.

\subsection{Immunoprecipitation}

For the precipitation of the antibody-protein complex out of a cell lysate, protein A/G-beads (\#PRAG25-A5-5, Alpha Diagnostics Intl., San Antonio, TX, USA) were used, as described in [48]. Further details can be found in Supplementary Materials and Methods. 


\subsection{Cell Cycle Analysis}

Synemin-depleted un- and irradiated SAS cells cultured for 24, 48 and $72 \mathrm{~h}$ were incubated with $10 \mathrm{mM}$ BrdU (BD Biosciences) for $10 \mathrm{~min}$. Cells were harvested using $1 \times$ trypsin/EDTA, fixed in ice cold $80 \%$ ethanol for $10 \mathrm{~min}$ and incubated for $10 \mathrm{~min}$ with $0.01 \%$ RNase A (Sigma-Aldrich), followed by 30 min incubation with $2 \mathrm{~N} \mathrm{HCl}$ (Sigma-Aldrich) and 0.5\% Triton-X-100/PBS (Roth, Karlsruhe, Germany). Subsequently, mouse anti-BrdU antibodies and propidium iodide (Sigma-Aldrich) were added for the detection of incorporated BrdU and total DNA content. Cell cycle distribution was determined using an FACS Calibur (BD Biosciences) and analyzed using the FlowJo software (version 7.6.2).

\subsection{Data Analysis}

The means \pm standard deviation (SD) of at least three independent biological experiments (indicated as $n$ ) were calculated with reference to controls defined in total numbers or 1.0. For statistical significance, two-sided Student's $t$-test was performed using Microsoft Excel 2003. A $p$-value of less than 0.05 was considered statistically significant. For foci experiments, one-way ANOVA, followed by post-hoc analysis using Turkey's correction, was used.

\section{Conclusions}

In summary, our data pinpoint the multifaceted roles of intermediate filaments and the regulatory complexity of DNA repair processes. ATM-dependently, synemin serves as a scaffold for DNA-PKcs and co-determines DNA double strand break repair upon genotoxic injury. The interactions of synemin, DNA-PKcs and ATM further underscore the concept of cytoarchitectural elements as key co-regulators of nuclear events. In this context, future investigations are warranted to elucidate the associated aspects of the DNA damage response, such as the cytoplasmic-to-nuclear shuttling of DNA repair proteins and chromatin reorganization.

Supplementary Materials: The following are available online at http://www.mdpi.com/2072-6694/12/7/1717/s1, Figure S1: UTSCC15 cells stably expressing EGFP-53BP1. Figure S2: Identification of focal adhesion proteins (FAP) affecting cell survival and radiosensitivity. Figure S3: Identification of focal adhesion proteins (FAP) affecting cell survival and radiosensitivity. Figure S4: Identification of focal adhesion proteins (FAPs) affecting DNA repair. Figure S5: Identification of focal adhesion proteins affecting cell survival, radiosensitivity and DNA repair. Figure S6: Altered expression of synemin expression in HNSCC. Figure S7: Synemin functions in NHEJ but not HR. Figure S8: Synemin functions in non-homologous end joining. Figure S9: Function of synemin in cell cycling. Figure S10: Synemin/DNA-PKcs co-control DSB repair and co-interact with each other. Figure S11: Expression of different Synemin constructs. Figure S12: Compilation of uncropped immunoblots for all the figures. Table S1: List of focal adhesion proteins selected for the screen library according to the Integrin Adhesome described by Horton et al., 2015. Table S2: Enhancement ratios of the plating efficiency of cells under FAP library knockdown. The table contains the mean and the p-value for each silenced protein. Table S3: Enhancement ratios of surviving fraction of cells upon FAP knockdown and 6 Gy X-Ray exposure. The table contains the mean and the p-value for each silenced protein. Table S4: Primary antibodies. Table S5: Secondary antibodies. Table S6: RNAi sequences and morpholinos. Table S7: Primers.

Author Contributions: Conceptualization, S.S.D., A.V. and N.C.; methodology, S.S.D., S.F. and E.D.; investigation, S.S.D.; formal analysis, S.S.D. and A.V.; resources, K.B.; writing-original draft, S.S.D., A.V. and N.C.; writing-review and editing, S.S.D., A.V. and N.C.; visualization, S.S.D., A.V. and N.C.; supervision, N.C.; project administration, N.C.; funding acquisition, N.C. All authors read and approved the final manuscript.

Funding: This project has received funding from the European Union's Horizon 2020 research and innovation program under the Marie Skłodowska-Curie grant agreement No. 642623 (to N.C.) and Deutsche Krebshilfe e.V. (70112151 to N.C.).

Acknowledgments: We are grateful to J. Bartek (University of Copenhagen, Denmark) for the pEGFP-c1-53BP1 and to R. J. Bloch (University of Maryland, USA) for the mCherry-Synemin plasmid. The authors thank Inga Lange for the technical assistance and Wei-Chun Lee for the support on method and library development.

Conflicts of Interest: The authors declare no conflict of interest. 


\section{References}

1. Bolderson, E.; Richard, D.J.; Zhou, B.-B.S.; Khanna, K.K. Recent advances in cancer therapy targeting proteins involved in DNA double-strand break repair. Clin. Cancer Res. 2009, 15, 6314-6320. [CrossRef]

2. Blackford, A.N.; Jackson, S.P. ATM, ATR, and DNA-PK: The trinity at the heart of the dna damage response. Mol. Cell 2017, 66, 801-817. [CrossRef] [PubMed]

3. Borgmann, K.; Köcher, S.; Kriegs, M.; Mansour, W.Y.; Parplys, A.C.; Rieckmann, T.; Rothkamm, K. DNA repair. Recent Results Cancer Res. 2016, 198, 1-24. [CrossRef] [PubMed]

4. Minten, E.V.; Yu, D.S. DNA repair: Translation to the clinic. Clin. Oncol. 2019, 31, 303-310. [CrossRef] [PubMed]

5. Chang, H.H.Y.; Pannunzio, N.R.; Adachi, N.; Lieber, M.R. Non-homologous DNA end joining and alternative pathways to double-strand break repair. Nat. Rev. Mol. Cell Biol. 2017, 18, 495-506. [CrossRef]

6. Bakkenist, C.J.; Kastan, M.B. Chromatin perturbations during the DNA damage response in higher eukaryotes. DNA Repair (Amst.) 2015, 36, 8-12. [CrossRef]

7. Bissell, M.J.; Weaver, V.M.; Lelièvre, S.A.; Wang, F.; Petersen, O.W.; Schmeichel, K.L. Tissue structure, nuclear organization, and gene expression in normal and malignant breast. Cancer Res. 1999, 59, 1757s-1763s.

8. Eke, I.; Cordes, N. Focal adhesion signaling and therapy resistance in cancer. Semin. Cancer Biol. 2015, 31, 65-75. [CrossRef]

9. Zienert, E.; Eke, I.; Aust, D.; Cordes, N. LIM-only protein FHL2 critically determines survival and radioresistance of pancreatic cancer cells. Cancer Lett. 2015, 364. [CrossRef]

10. Eke, I.; Zscheppang, K.; Dickreuter, E.; Hickmann, L.; Mazzeo, E.; Unger, K.; Krause, M.; Cordes, N. Simultaneous $\beta 1$ integrin-EGFR targeting and radiosensitization of human head and neck cancer. J. Natl. Cancer Inst. 2015, 107, 1-11. [CrossRef]

11. Dickreuter, E.; Eke, I.; Krause, M.; Borgmann, K.; Van Vugt, M.A.; Cordes, N. Targeting of $\beta 1$ integrins impairs DNA repair for radiosensitization of head and neck cancer cells. Oncogene 2016, 35, 1353-1362. [CrossRef] [PubMed]

12. Kotula, E.; Faigle, W.; Berthault, N.; Dingli, F.; Loew, D.; Sun, J.S.; Dutreix, M.; Quanz, M. DNA-PK target identification reveals novel links between DNA repair signaling and cytoskeletal regulation. PLoS ONE 2013, 8. [CrossRef] [PubMed]

13. Diaz Osterman, C.J.; Ozmadenci, D.; Kleinschmidt, E.G.; Taylor, K.N.; Barrie, A.M.; Jiang, S.; Bean, L.M.; Sulzmaier, F.J.; Jean, C.; Tancioni, I.; et al. FAK activity sustains intrinsic and acquired ovarian cancer resistance to platinum chemotherapy. Elife 2019, 8. [CrossRef] [PubMed]

14. He, L.; Wang, X.; Liu, K.; Wu, X.; Yang, X.; Song, G.; Zhang, B.; Zhong, L. Integrative PDGF/PDGFR and focal adhesion pathways are downregulated in ERCC1-defective non-small cell lung cancer undergoing sodium glycididazole-sensitized cisplatin treatment. Gene 2019, 691, 70-76. [CrossRef]

15. Jin, S.; Kharbanda, S.; Mayer, B.; Kufe, D.; Weaver, D.T. Binding of Ku and c-Abl at the kinase homology region of DNA-dependent protein kinase catalytic subunit. J. Biol. Chem. 1997, 272, 24763-24766. [CrossRef]

16. Guérette, D.; Khan, P.A.; Savard, P.E.; Vincent, M. Molecular evolution of type VI intermediate filament proteins. BMC Evol. Biol. 2007, 7, 164. [CrossRef]

17. Jing, R.; Pizzolato, G.; Robson, R.M.; Gabbiani, G.; Skalli, O. Intermediate filament protein synemin is present in human reactive and malignant astrocytes and associates with ruffled membranes in astrocytoma cells. Glia 2005, 50, 107-120. [CrossRef]

18. Sun, N.; Huiatt, T.W.; Paulin, D.; Li, Z.; Robson, R.M. Synemin interacts with the LIM domain protein zyxin and is essential for cell adhesion and migration. Exp. Cell Res. 2010, 316, 491-505. [CrossRef]

19. Hehlgans, S.; Eke, I.; Cordes, N. Targeting FAK radiosensitizes 3-dimensional grown human HNSCC cells through reduced Akt1 and MEK1/2 signaling. Int. J. Radiat. Oncol. Biol. Phys. 2012, 83, e669-e676. [CrossRef]

20. Eke, I.; Koch, U.; Hehlgans, S.; Sandfort, V.; Stanchi, F.; Zips, D.; Baumann, M.; Shevchenko, A.; Pilarsky, C.; Haase, M.; et al. PINCH1 regulates Akt1 activation and enhances radioresistance by inhibiting PP1alpha. J. Clin. Investig. 2010, 120, 2516-2527. [CrossRef]

21. Eke, I.; Deuse, Y.; Hehlgans, S.; Gurtner, K.; Krause, M.; Baumann, M.; Shevchenko, A.; Sandfort, V.; Cordes, N. $\beta 1$ Integrin/FAK/cortactin signaling is essential for human head and neck cancer resistance to radiotherapy. J. Clin. Investig. 2012, 122, 1529-1540. [CrossRef] [PubMed] 
22. Network, T.C.G.A. Comprehensive genomic characterization of head and neck squamous cell carcinomas. Nature 2015, 517, 576-582. [CrossRef] [PubMed]

23. Xue, Y.; Ren, J.; Gao, X.; Jin, C.; Wen, L.; Yao, X. GPS 2.0, a tool to predict kinase-specific phosphorylation sites in hierarchy. Mol. Cell. Proteom. 2008, 7, 1598-1608. [CrossRef] [PubMed]

24. Mansour, W.Y.; Bogdanova, N.V.; Kasten-Pisula, U.; Rieckmann, T.; Köcher, S.; Borgmann, K.; Baumann, M.; Krause, M.; Petersen, C.; Hu, H.; et al. Aberrant overexpression of miR-421 downregulates ATM and leads to a pronounced DSB repair defect and clinical hypersensitivity in SKX squamous cell carcinoma. Radiother. Oncol. 2013, 106, 147-154. [CrossRef]

25. Sampietro, D.; Sámano-Sánchez, H.; Davey, N.E.; Sharan, M.; Mészáros, B.; Gibson, T.J.; Kumar, M. Conserved SQ and QS motifs in bacterial effectors suggest pathogen interplay with the ATM kinase family during infection. bioRxiv 2018, 364117. [CrossRef]

26. Pickup, M.W.; Mouw, J.K.; Weaver, V.M. The extracellular matrix modulates the hallmarks of cancer. EMBO Rep. 2014, 15, 1243-1253. [CrossRef]

27. Mahajan, K.; Mahajan, N.P. Cross talk of tyrosine kinases with the DNA damage signaling pathways. Nucleic Acids Res. 2015, 43, 10588-10601. [CrossRef]

28. Cabodi, S.; Del Pilar Camacho-Leal, M.; Di Stefano, P.; Defilippi, P. Integrin signalling adaptors: Not only figurants in the cancer story. Nat. Rev. Cancer 2010, 10, 858-870. [CrossRef]

29. Tang, K.-J.; Constanzo, J.D.; Venkateswaran, N.; Melegari, M.; Ilcheva, M.; Morales, J.C.; Skoulidis, F.; Heymach, J.V.; Boothman, D.A.; Scaglioni, P.P. Focal adhesion kinase regulates the DNA damage response and its inhibition radiosensitizes mutant KRAS lung cancer. Clin. Cancer Res. 2016, 22, 5851-5863. [CrossRef]

30. Vehlow, A.; Cordes, N. Invasion as target for therapy of glioblastoma multiforme. Biochim. Biophys. Acta 2013, 1836, 236-244. [CrossRef]

31. Williams, K.E.; Bundred, N.J.; Landberg, G.; Clarke, R.B.; Farnie, G. Focal adhesion kinase and Wnt signaling regulate human ductal carcinoma in situ stem cell activity and response to radiotherapy. Stem Cells 2015, 33, 327-341. [CrossRef] [PubMed]

32. García-Pelagio, K.P.; Chen, L.; Joca, H.C.; Ward, C.; Jonathan Lederer, W.; Bloch, R.J. Absence of synemin in mice causes structural and functional abnormalities in heart. J. Mol. Cell. Cardiol. 2018, 114, 354-363. [CrossRef] [PubMed]

33. Parlakian, A.; Paulin, D.; Izmiryan, A.; Xue, Z.; Li, Z. Intermediate filaments in peripheral nervous system: Their expression, dysfunction and diseases. Rev. Neurol. (Paris) 2016, 172, 607-613. [CrossRef] [PubMed]

34. Quick, Q.; Paul, M.; Skalli, O. Roles and potential clinical applications of intermediate filament proteins in brain tumors. Semin. Pediatr. Neurol. 2015, 22, 40-48. [CrossRef]

35. Noetzel, E.; Rose, M.; Sevinc, E.; Hilgers, R.-D.; Hartmann, A.; Naami, A.; Knüchel, R.; Dahl, E. Intermediate filament dynamics and breast cancer: Aberrant promoter methylation of the synemin gene is associated with early tumor relapse. Oncogene 2010, 29, 4814-4825. [CrossRef]

36. Pitre, A.; Davis, N.; Paul, M.; Orr, A.W.; Skalli, O. Synemin promotes AKT-dependent glioblastoma cell proliferation by antagonizing PP2A. Mol. Biol. Cell 2012, 23, 1243-1253. [CrossRef]

37. Liu, Y.-H.; Cheng, C.-C.; Lai, Y.-S.; Chao, W.-T.; Pei, R.-J.; Hsu, Y.-H.; Ho, C.-C. Synemin down-regulation in human hepatocellular carcinoma does not destabilize cytoskeletons in vivo. Biochem. Biophys. Res. Commun. 2011, 404, 488-493. [CrossRef]

38. Khanamiryan, L.; Li, Z.; Paulin, D.; Xue, Z. Self-assembly incompetence of synemin is related to the property of its head and rod domains. Biochemistry 2008, 47, 9531-9539. [CrossRef]

39. Bilak, S.R.; Sernett, S.W.; Bilak, M.M.; Bellin, R.M.; Stromer, M.H.; Huiatt, T.W.; Robson, R.M. Properties of the novel intermediate filament protein synemin and its identification in mammalian muscle. Arch. Biochem. Biophys. 1998, 355, 63-76. [CrossRef]

40. Geisler, F.; Leube, R. Epithelial intermediate filaments: Guardians against microbial infection? Cells 2016, 5, 29. [CrossRef]

41. Marceau, N.; Schutte, B.; Gilbert, S.; Loranger, A.; Henfling, M.E.R.; Broers, J.L.V.; Mathew, J.; Ramaekers, F.C.S. Dual roles of intermediate filaments in apoptosis. Exp. Cell Res. 2007, 313, 2265-2281. [CrossRef] [PubMed]

42. Rothballer, A.; Kutay, U. The diverse functional LINCs of the nuclear envelope to the cytoskeleton and chromatin. Chromosoma 2013, 122, 415-429. [CrossRef] [PubMed]

43. Spichal, M.; Fabre, E. The emerging role of the cytoskeleton in chromosome dynamics. Front. Genet. 2017, 8, 60. [CrossRef] [PubMed] 
44. Lottersberger, F.; Karssemeijer, R.A.; Dimitrova, N.; De Lange, T. 53BP1 and the LINC complex promote microtubule-dependent DSB mobility and DNA repair. Cell 2015, 163, 880-893. [CrossRef] [PubMed]

45. Berger, N.D.; Stanley, F.K.T.; Moore, S.; Goodarzi, A.A. ATM-dependent pathways of chromatin remodelling and oxidative DNA damage responses. Philos. Trans. R. Soc. B Biol. Sci. 2017, 372, 20160283. [CrossRef]

46. Jin, S.; Cordes, N. ATM controls DNA repair and mitochondria transfer between neighboring cells. Cell Commun. Signal. 2019, 17, 144. [CrossRef]

47. Vehlow, A.; Klapproth, E.; Jin, S.; Hannen, R.; Hauswald, M.; Bartsch, J.-W.; Nimsky, C.; Temme, A.; Leitinger, B.; Cordes, N. Interaction of discoidin domain receptor 1 with a 14-3-3-Beclin-1-Akt1 complex modulates glioblastoma therapy sensitivity. Cell Rep. 2019, 26, 3672-3683.e7. [CrossRef]

48. Kittler, R.; Putz, G.; Pelletier, L.; Poser, I.; Heninger, A.K.; Drechsel, D.; Fischer, S.; Konstantinova, I.; Habermann, B.; Grabner, H.; et al. An endoribonuclease-prepared siRNA screen in human cells identifies genes essential for cell division. Nature 2004, 432, 1036-1040. [CrossRef]

49. Horton, E.R.; Byron, A.; Askari, J.A.; Ng, D.H.J.; Millon-Frémillon, A.; Robertson, J.; Koper, E.J.; Paul, N.R.; Warwood, S.; Knight, D.; et al. Definition of a consensus integrin adhesome and its dynamics during adhesion complex assembly and disassembly. Nat. Cell Biol. 2015, 17, 1577-1587. [CrossRef]

50. Pierce, A.J.; Johnson, R.D.; Thompson, L.H.; Jasin, M. XRCC3 promotes homology-directed repair of DNA damage in mammalian cells service XRCC3 promotes homology-directed repair of DNA damage in mammalian cells. Genes Dev. 1999, 13, 2633-2638. [CrossRef]

51. Krajewska, M.; Heijink, A.M.; Bisselink, Y.J.W.M.; Seinstra, R.I.; Silljée,H.H.W.; De Vries, E.G.E.; Van Vugt, M.A.T.M. Forced activation of Cdk1 via wee1 inhibition impairs homologous recombination. Oncogene 2013, 32, 3001-3008. [CrossRef] [PubMed]

(C) 2020 by the authors. Licensee MDPI, Basel, Switzerland. This article is an open access article distributed under the terms and conditions of the Creative Commons Attribution (CC BY) license (http://creativecommons.org/licenses/by/4.0/). 